Pérez Sánchez. En cualquier caso y según dicho profesor, se trataría de una obra que efectivamente pertenece a Bartolomé Román.

Por nuestra parte nos limitamos exclusivamente a darlo a conocer, aunque no ocultemos, la admiración que produce cuando se contemplan detenidamente todos sus pormenores.

\title{
B. VelASCO
}

\section{MAESTROS Y CANTEROS EN LAS OBRAS DEL MONASTERIO DE NUESTRA SEÑORA DE LA ASUNCIÓN (ALMAGRO)}

El monasterio de Nuestra Señora de la Asunción en Almagro acogió en el pasado a una comunidad femenina de la Orden de Calatrava. Según los distintos autores que han tratado el tema, la fundación de esta casa estuvo directamente relacionada con los piadosos deseos del Comendador Mayor de la Orden, Don Gutierre de Padilla. Este personaje mandó levantar un hospital en la localidad manchega, pero el proyecto era de tal envergadura que el Capítulo General celebrado en 1523 decidió modificarlo, ordenándose la construcción de un monasterio y que éste conviviese con un hospital de menores dimensiones ${ }^{1}$.

El valor de este conjunto monumental es incuestionable ya que nos encontramos ante un gran ejemplo de nuestra arquitectura del siglo xvi. Sin embargo, su relevancia en el plano artístico no se ha visto recompensada con un estudio en el que se analicen de forma pormenorizada los distintos aspectos de su fábrica. Si nos centramos en el problema que ahora nos interesa, es decir, en el de los artífices que trabajaron en este edificio, nos encontramos con un panorama prácticamente virgen ya que, hasta el momento, no se había recurrido de forma sistemática a las fuentes documentales. Contábamos, tan solo, con una escueta referencia a Enrique Egas el Mozo fechada en $1564^{2}$ y con una breve mención a la figura de un maestro poco conocido, el maestro Balbás, que estaría relacionado con las obras realizadas en el monasterio durante los primeros años del siglo XVI, concretamente en $1523^{3}$. Para remediar en lo posible esta situación, nuestro trabajo aporta varios datos de gran importancia sobre los artistas que trabajaron en la fábrica del edificio, datos que hemos encontrado al analizar dos fuentes que habían permanecido inéditas hasta ahora ${ }^{4}$.

El primer documento que vamos a utilizar está fechado en 1546. Se trata de la visita realizada al monasterio por el prior del Sacro Convento de Calatrava y por frey Francisco Carrillo de Guzmán, comendador de Vallaga. Entre la documentación generada por los autos que se llevaron a cabo durante esta visita nos encontramos con un pliego fechado el 20 de diciembre de 1544 en el que se recogen los nombres de cinco canteros que trabajaron ese año en las obras del edificio, especificando la labor que realizaron y la cantidad que recibieron por su trabajo. Lucas Mateo es el primer maestro al que se hace referencia, afirmando que cobró 2.400 maravedís por labrar doze varas de perpiaños para los arcos a presçio cada vara de a dozientos maravedis. A continuación se menciona a Francisco de Jerez, que percibió 2.200 maravedís por realizar otras once varas de perpiaños, y a Gabriel Romano, que cobró 1.700 maravedís por

\footnotetext{
I Díez de Baldeón, C.: Almagro. Arquitectura y sociedad, Toledo, 1993, p. 153.

2 Díez de Baldeón, C.: op. cit., p. 160.

3 Saínz Magaña, E. y Herrera Maldonado, E.: «Arte Moderno» en Ciudad Real y su provincia, Tomo III, Sevilla, 1996, p. 102.

4 Archivo Histórico Nacional, Ordenes Militares, Archivo Judicial de Toledo, pleito 43.132. Bajo esta signatura se hallan catalogados varios libros manuscritos que contienen distinta información sobre el convento.
} 
hacer diez varas de cruzeros segunderos e terçeretes. Tras la referencia a estos dos maestros nos encontramos con Juan Egas que se encargó de terminar ocho varas e media de los dichos cruzeros, recibiendo por ello 1.445 maravedís. Finalmente, se menciona a Francisco Hernández que realizó otras diez varas de cruceros y segunderos.

El segundo documento que hemos podido localizar es algo posterior en el tiempo. Nos estamos refiriendo a la visita realizada en 1553 por frey Iñigo de Ayala, comendador de Calatrava la Vieja, y frey Lorenzo Suárez de Figueroa, prior de Alcañiz; dos miembros de la Orden que, entre otras cosas, se encargaron de revisar las cuentas de la abadesa del monasterio. Los datos aportados por este documento son también de gran importancia, aunque en esta ocasión sólo se mencione a dos maestos. Para empezar, entre los gastos efectuados en 1552 nos encontramos con 28.695 maravedís que se entregaron a un cantero llamado Juan Navarro por la piedra que a traydo para la obra de la yglesia. Cantidad a la que deberíamos añadir los nueve reales que se pagaron a maese Enrique de su salario de tres dias que se ocupo en hazer contramoldes para la piedra que se trahe para la casa digo para la yglesia.

Por último, en las cuentas del año siguiente se incluyen 5.448 maravedís que se dieron a Juan Navarro de lo que se le debía de la piedra que había traído al monasterio y tres reales que se entregaron a maese Enrique de un dia que se ocupo en medir la piedra. A nuestro juicio, el maese Enrique al que se refiere el documento no sería otro que Enrique Egas el Mozo; estamos, por tanto, ante el primer documento en el que se recoge la actividad que estaba realizando este maestro en el monasterio y el salario que percibía por su trabajo. Por otra parte, si tenemos en cuenta el dato que nos facilitaba la visita de 1544 en torno a la figura de Juan Egas y lo relacionamos con la información que aporta el segundo documento, nos encontramos con la existencia de una indudable vinculación familiar entre esta saga de maestros y la fábrica del monasterio; aunque, por el momento, no sepamos cual era el parentesco que unía a estos dos artistas.

Las referencias que acabamos de presentar son, sin lugar a dudas, enormemente importantes. El hecho de poder identificar a varios de los canteros que participaron en las obras de este monasterio y conocer el trabajo que llevaron a cabo durante un período de tiempo muy concreto nos brinda la posibilidad de llegar a ciertas conclusiones y, sobre todo, de abrir nuevas perspectivas que hasta ahora ni siquiera podíamos aventurar. En primer lugar, el contenido de la primera visita nos sirve para datar la construcción de las bóvedas que cubren la iglesia. Aunque en el encabezamiento del documento se afirme que los maestros relacionados en él habían labrado en la piedra del monesterio y ospital quel señor Don Gutierre de Padilla mando hazer en esta villa, la propia fisonomía que presenta el conjunto no deja lugar a dudas. El texto nos estaría hablando, en buena medida, del cerramiento de la iglesia conventual; siendo vitales, en este sentido, las referencias a los distintos nervios de las bóvedas.

Por otra parte, resulta obvio que en torno a la imponente fábrica del monasterio y del hospital se generó un gran taller en el que se dieron cita numerosos artistas. Este taller debió ejercer una poderosa influencia en toda la zona, dejando su huella en otros edificios religiosos de la comarca que también estamos estudiando como la iglesia parroquial de Moral de Calatrava. La relevancia de los maestros que intervinieron en la obra resulta evidente, sobre todo en el caso de Enrique Egas el Mozo; sin embargo, para finalizar este breve trabajo, me gustaría hacer hincapié en la figura de Gabriel Romano. Hoy por hoy resulta imposible identificar con un mínimo de precisión a este cantero pero el topónimo que acompaña a su nombre de pila nos permite lanzar una hipótesis que, en principio, podría parecer arriesgada: la participación de mano de obra italiana en la fábrica de las Calatravas. Esta afirmación no resulta nada descabellada si tenemos en cuenta la costumbre que existía en la época de designar a las personas por su lugar de origen. Un buen ejemplo de esta práctica, que también se puede percibir en los 
nombres de otros artistas que participaron en las obras como Francisco de Jerez, es la figura de ese Ferrando Spagnuolo que trabajó con Leonardo en la batalla de Anghiari y que, tras su período de aprendizaje con el maestro, regresó a España para proseguir su labor artística ${ }^{5}$. En este sentido, la presencia de artífices italianos en la obra del monasterio de la Asunción nos ayuda a entender mucho mejor buena parte tanto del léxico formal como de la decoración de determinadas partes del edificio, en especial de su bello claustro, abriéndonos nuevas posibilidades de interpretación que intentaremos explorar en futuros trabajos.

José JAVIER BARRANQuero CONTENTO

${ }^{5}$ Condorelli, A.: «Consideraciones sobre "Ferrando Spagnuolo" y otros maestros ibéricos», Archivo Español de Arte, 284, 1998, pp. 345-360. 